\title{
O PROCESSO DE REESCRITA NO ENSINO DO GÊNERO CARTA DE RECLAMAÇÃO
}

\author{
Maria Ladjane dos Santos Pereira* \\ Benedito Gomes Bezerra**
}

Resumo: Neste trabalho, discutimos como a reescrita pode subsidiar o ensino do gênero carta de reclamação, de modo a instrumentalizar os estudantes a utilizarem-se dos mecanismos linguísticos adequados para que esse gênero venha a cumprir o seu propósito comunicativo (SWALES, 1990, 2004) em situações autênticas de uso. Para tanto, recorremos ao ciclo de ensino-aprendizagem australiano (MARTIN, 2016; ROSE, 2016) a fim de esboçar um percurso teórico que permita articular os aspectos sociais e os traços linguísticos da carta de reclamação. O estudo baseou-se em um corpus composto de 12 cartas de reclamação, escritas por estudantes da IV fase da EJA. Os resultados apontam para melhorias no texto a partir da reescrita, orientada por meio de bilhetes, que levam ao cumprimento do propósito comunicativo desse gênero.

Palavras-chave: Carta de reclamação. Ciclo de Ensino-Aprendizagem. Reescrita.

Abstract: In this paper, we discuss how the rewriting can subsidize the teaching of the complaint letter genre in order to equip students to use the appropriate linguistic mechanisms so that this genre will fulfill its communicative purpose (SWALES, 1990, 2004) in authentic situations of use. To that end, we use the Australian teaching-learning cycle MARTIN (2016) e ROSE (2016) in order to outline a theoretical path that allows articulating the social aspects and the linguistic features of the complaint letter. The study was based on a corpus composed of 12 letters of complaint, written by students of the fourth phase of the EJA. The results point to improvements in the text after rewriting, oriented through guiding notes, which that lead to the fulfillment of the communicative purpose of this genre.

Keywords: Complaint letter. Teaching-learning cycle. Rewriting.

\section{Introdução}

O ensino de gêneros costuma ser bastante discutido no cenário acadêmico, quer em termos da orientação franco-suíça, como em Schneuwly e Dolz (2004) e Bronckart (2006), quer na perspectiva australiana, com os trabalhos dos pesquisadores da Escola de Sydney, como também na perspectiva norte-americana com as publicações de Devitt (2004). Contudo, sua aplicação em sala de aula ainda é passível de muitas discussões e análises, pois devemos reforçar a necessidade de se perceber os gêneros como ação social que, apesar de convencionalmente serem ensinados na escola, antes de tudo, circulam fora dela. Com isso, emerge um imperativo de maior entendimento quanto ao uso, já que, assim como Bazerman (2006), concordamos que os gêneros organizam a vida em sociedade.

Elencamos como principal objetivo investigar como o processo de reescrita pode subsidiar o aluno na produção da carta de reclamação (CR), de modo que o gênero, em situação escolar, aproxime-se de circunstâncias de uso autêntico e cumpra seus propósitos comunicativos. Assim, empreendemos nossos esforços em analisar a utilização da correção textual-interativa, nos processos de revisão e na reescrita, como etapa relevante para o cumprimento dos propósitos comunicativos da CR; assim como, relacionar a reescrita do aluno às orientações dadas pelo professor; além de desenvolver proposta didática de orientação para a produção textual, a partir do ciclo de ensino-aprendizagem australiano, com foco na correção do professor e reescrita do aluno.

\footnotetext{
${ }^{*}$ Doutoranda em Ciências da Linguagem (UNICAP). E-mail: ladjane_pereira@ hotmail.com.

${ }^{* *}$ Doutor em Linguística (UNICAP/UPE). E-mail: beneditobezerra@ gmail.com.
} 
Ao aprender a produzir uma carta de reclamação, por exemplo, o aluno poderá exercer, efetivamente, sua cidadania na luta pelos seus direitos. A carta de reclamação poderá ser efetivamente utilizada em casos como a compra de algum produto que, porventura venha com defeito, ou, ainda, na reivindicação de melhores condições de saneamento para a comunidade. Nossa tese é de que a escola poderá oferecer aos alunos instrumentos para o exercício da cidadania, caso trabalhe com a concepção de gêneros como ação social (MILLER, 2009).

A proposta de intervenção relatada neste trabalho foi desenvolvida com uma turma de Educação de Jovens e Adultos (EJA) da IV Fase (equivalente ao $9^{\circ}$ Ano do Ensino Fundamental), de uma escola da rede municipal de Arcoverde/PE, valendo-se de um corpus de cartas de reclamação, com foco na reescrita, norteada pelas orientações dadas pela professora. Para efeito de análise, constituem o corpus a segunda e terceira versões da carta, uma vez que na primeira, a maioria dos estudantes a desconhece, enquanto meio para efetivar as reclamações. Dessa maneira, na versão inicial, a maioria narrou possíveis ações de como reclamariam, de modo que apenas um dos textos poderia ser caracterizado como uma reclamação.

Dessa forma, este trabalho está estruturado em cinco tópicos, a saber: inicialmente, tecemos considerações em torno das pedagogias de gêneros, por meio do ensino implícito ou explícito de gêneros. No segundo tópico, discutimos a organização do ciclo de ensinoaprendizagem australiano. Já no terceiro, enfocamos os processos de revisão e reescrita. Mais adiante, exploramos o encaminhamento metodológico e a análise dos textos. Por fim, apresentamos nossas considerações, por ora, finais.

\section{Ensino implícito e explícito de gêneros: o que apontam as teorias}

A discussão em torno do ensino de gênero ocorre sob diferentes enfoques, a depender das teorias que o orientam. Para Chapman (1999), no que tange às concepções de gêneros aplicadas à educação básica, há um foco triplo, de modo que a cada uma dessas perspectivas, podemos associar diferentes percursos teóricos: o primeiro trata sobre aprender gêneros, em consonância com a utilização de estratégias retóricas, sem que haja uma modelagem daquele gênero. O segundo foco diz respeito a aprender por meio de gêneros, situação em que o gênero é visto como processo de aprendizagem, com estratégias específicas para adquiri-lo. Por último, aprender sobre gêneros remete à percepção de gênero como recurso cultural. Para os defensores da primeira perspectiva, cuja compreensão parte de não se apresentar uma modelagem, por meio da apresentação de um exemplar de texto no gênero a ser ensinado, sem maior atenção às estratégias específicas para adquiri-lo, há um direcionamento maior à necessidade de inserção no ambiente autêntico do gênero, de cuja perspectiva decorre o ensino implícito.

Ao partilhar disso, em crítica ao ensino explícito de gênero, Bawarshi e Reiff (2013, p. 114) concordam com Freadman (1994) ao explicarem que

[...] quando um gênero é abstraído do seu contexto de uso e ensinado explicitamente no contexto da sala de aula, ou quando um gênero de um contexto disciplinar ou público é simulado noutro contexto, digamos numa sala de aula, esse gênero é recortado de seu ambiente semiótico, e o pareamento do gênero explicado ou simulado "com sua apreensão adequada é rompido".

Nesse aspecto, percebemos a complexidade de se "ensinar" gêneros, pois há uma infinidade de contextos em que os gêneros se inter-relacionam, nos quais a escola não poderia estar de fato imersa ou dos quais não poderia fazer uma reprodução fiel. Desse modo, haverá nessa tentativa um "rompimento na apreensão", ou seja, não havendo o contato com o contexto de uso de determinado gênero, é provável que o usuário não desenvolva a apreensão adequada. Filiados a isso, Bawarshi e Reiff (2013, p. 113) defendem que

[...] o conhecimento da apreensão é conhecimento de quando e por que usar um gênero; como selecionar um gênero adequado em relação com outro ou outros; onde e a que custo apreender um gênero, ao 
longo da extensão de seu perfil de apreensão; como alguns gêneros citam explicitamente outros gêneros em sua apreensão, enquanto alguns só o fazem implicitamente, e assim por diante.

Porém, existem críticas ao ensino implícito de gêneros, talvez justificadas pelas escolhas teóricas que determinam o percurso didático e, consequentemente, levam a concepções distintas, como já afirmamos anteriormente. Um ponto para refletirmos inicialmente, pode ser: será que os estudantes estão em igualdade de condições de apreender gêneros, já que podem partilhar de contextos culturais e situacionais distintos?

Abordagens como o Inglês para Fins Específicos (ESP) e a Linguística SistêmicoFuncional (LSF) consideram de relevância pedagógica "tornar visível para estudantes desfavorecidos as conexões entre língua e função social incorporadas pelos gêneros" (BAWARSHI; REIFF, 2013, p. 62). Outro defensor dessa "pedagogia visível", Hyland (2004, p. 88) aponta que essa perspectiva busca ofertar aos estudantes produtores de texto uma compreensão explícita de como os textos se estruturam, bem como os levar a refletir em por que são escritos dessa forma. Assim, o ESP e a LSF, ainda que com públicos e abordagens distintas, concordam que o ensino explícito de gêneros pode proporcionar a estudantes desfavorecidos $o$ acesso aos variados gêneros.

Nesse sentido, compreendemos que recortar o gênero de seu ambiente autêntico, ensinando-o na escola, pode servir como estratégia para o desenvolvimento de competências que serão utilizadas posteriormente no seu convívio social. Logo, se na escola foram explorados os traços linguísticos que constituem o gênero articulados às ações sociais, é possível que esse conhecimento seja utilizado nas mais variadas situações de uso desse e de outros gêneros.

De acordo com Martin (2000, apud ROSE, 2009), a pedagogia baseada na escrita de gêneros, dita explícita, representa uma alternativa para pedagogias tradicionais e progressivas da linguagem, de modo que a pedagogia de gênero baseada na LSF, antes de se referir à linguagem em si, parte da noção dos propósitos sociais que levam à realização de gêneros escritos. Além disso, pressupõe a necessidade de um sistema de linguagem contextualizado, a partir de textos reais.

Martin e seus colegas sistêmicos consideram os gêneros como "processo social gradual e orientado por objetivos" (MARTIN, 2016, p. 37). Igualmente, podemos refletir que a LSF percebe o gênero como dotado de regularidades linguísticas ensináveis, como também que sua organização é orientada pela prática social, ao empreender o gênero de forma interativa, haja vista que são aplicadas marcas linguísticas, somadas às marcas contextuais, que se interrelacionam a fim de realizar os seus propósitos comunicativos.

Na pretensão de compreender como esse ensino pode ser possível, no tópico a seguir, apresentamos o modelo sistêmico-funcional australiano, construído em prol do ensino de gêneros a estudantes cujo acesso a esses textos é limitado. Convém ressaltar que o público-alvo da pesquisa foi constituída de uma turma de EJA, cujo acesso aos diversos gêneros parece ser, muitas vezes, restrito à escola.

\section{O Ciclo de Ensino-Aprendizagem da Linguística Sistêmico-Funcional}

De acordo com Martin (2016), a regra básica em que se baseia a pedagogia de gênero não é pedir aos alunos que escrevam de imediato. Antes, é preciso apresentar o gênero que se espera escrever por meio de exemplares do gênero instanciados em textos. Assim, os estudantes se envolvem na construção conjunta de um texto do mesmo gênero que, mais uma vez, funciona como molde para a construção individual.

Ao seguir a perspectiva do ciclo, Martin (2016, p. 61) reproduz a descrição detalhada das etapas que aparecem em Rose (2016), conforme segue: 
Figura 1 - Ciclo de ensino-aprendizagem

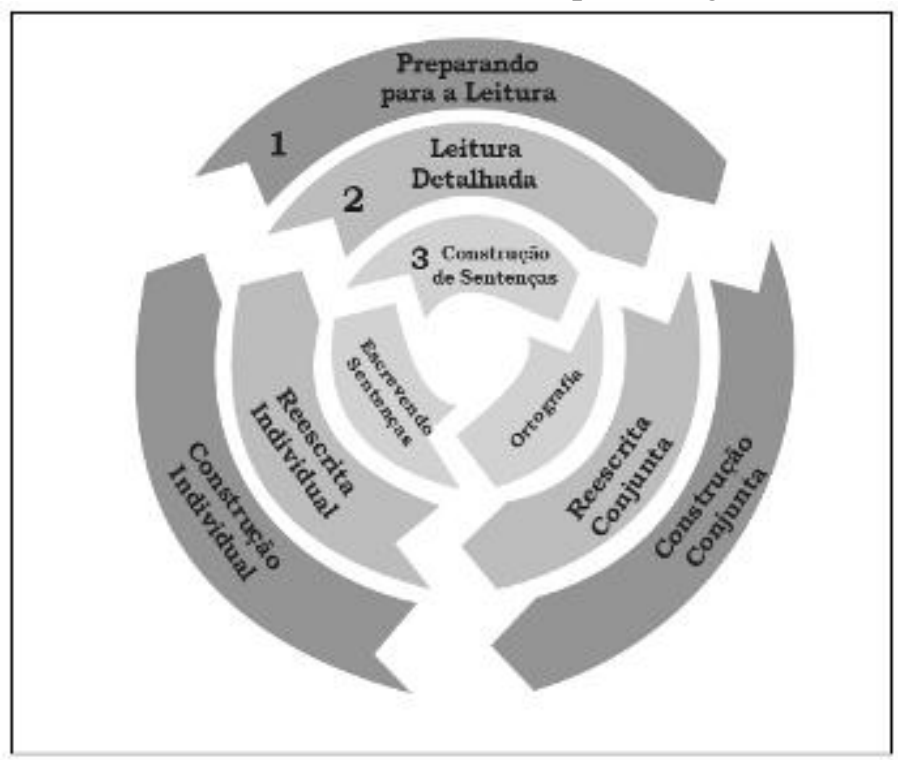

Fonte: Martin (2016, p. 61).

De acordo com Rose (2016), a etapa "preparando para a leitura" tem a função de permitir que todos os alunos sigam o texto que está sendo lido, bem como participem na elaboração das atividades durante e após a leitura. Esse estágio inclui dois elementos: a sinopse do campo do texto a ser lido e o sumário passo a passo de como o campo se desdobra por meio do gênero.

A preparação aparece com a função de um roteiro a ser seguido pelos estudantes, a partir dos elementos lexicais que constituem o texto. Nessa fase do ciclo, o fato de o estudante saber que a história que está sendo lida corresponde a uma narrativa com uma série de episódios e que muitos deles incluem uma certa configuração, como o problema e a resolução, talvez facilite a compreensão do gênero e, consequentemente, a forma como se organiza.

A etapa subsequente é a "leitura detalhada". Nela, o professor deve orientar os estudantes a lerem o texto em partes, identificando e discutindo o sentido de cada uma delas. A função dessa etapa é "permitir que todos os estudantes leiam a passagem com compreensão completa e fluência e reconheçam as escolhas linguísticas feitas pelo autor. Assim, eles podem reconhecê-las em outros textos para depois inseri-las em seus próprios" (ROSE, 2016, p. 323).

$\mathrm{Na}$ "reescrita conjunta", há um direcionamento a cada parte do texto, de modo que se levam em consideração, sobretudo, os aspectos gramaticais presentes nesses trechos. Essa técnica é importante para que os estudantes identifiquem os padrões de linguagem e os utilizem em situações semelhantes. Nessa fase, são exploradas algumas passagens do texto, previamente selecionadas pelo professor, a fim de que os estudantes exercitem questões de escolhas lexicais, gramaticais, discursivas feitas pelo autor para, a partir disso, reescrevê-las.

Na sequência, é o momento da "construção conjunta", em que o texto tomado por base é desconstruído para que os estudantes, que já conhecem a organização textual do gênero após terem passado pelas etapas anteriores, produzam um novo exemplar do gênero, coletivamente. Após essas etapas, vem a "construção individual" que serve para identificar os padrões linguísticos já apreendidos, a partir da modelagem do texto estudado, aplicando tais conhecimentos a novos campos e na produção de seus futuros textos.

A aplicação das etapas do ciclo reconhece e caracteriza a construção do texto como um processo sistemático, no qual o professor intervém sempre que necessário. Uma forma dessa intervenção se dá em torno de procedimentos de reescrita. Assim, o próximo tópico apresenta diferentes percepções acerca da reescrita, sobretudo como mediada pelo feedback do professor. Nesse sentido, julgou-se necessário ampliar a concepção de reescrita para além da visão defendida pelo ciclo. 


\section{A revisão e a reescrita}

Rose (2016) sugere que a reescrita, tal como apresentada no ciclo, é comparada à imitatio, da tradição retórica clássica, com exceção do fato de que as orientações fornecidas na leitura detalhada e na reescrita conjunta garantem que cada estudante tenha êxito nas tarefas. Entendemos, assim, que essa atividade, proposta no ato da reescrita conjunta, é aquela que segue os moldes do texto escolhido pelo professor, já explorado na leitura detalhada.

Neste trabalho, a reescrita é orientada pelo professor por meio de bilhetes (BUIN, 2006; RUIZ, 2013), no sentido de levar a compreender a necessidade da reescrita. Isso poderá contribuir para a constituição do gênero no cumprimento de sua prática social e não simplesmente visando a atender a uma demanda gramatical, indo mais adiante, para não se ater ao forte entendimento de produzir texto no intuito de obter nota. Ao revisar os textos dos alunos, Ruiz (2013), embasada em Serafini (1995), elenca alguns tipos de correção comumente realizadas pelo professor - a resolutiva, a indicativa e a classificatória - e, após os desdobramentos de sua própria pesquisa, encontra traços de um tipo de correção que denomina textual-interativa.

Por assim dizer, Ruiz (2013) afirma que a escrita por parte do aluno depende do modo como o professor lê o seu texto, pois, para a autora, leituras que consideram o texto, na sua totalidade, como uma unidade de sentido, são mais bem-sucedidas que as que enfocam as unidades menores do texto. Assim, a correção textual-interativa parece ser uma estratégia que pode facilitar o diálogo entre o professor e o aluno, de modo que aquele pode sinalizar as mudanças a serem feitas para além dos aspectos da superfície textual, sobretudo, com ênfase nos aspectos discursivos. Esses últimos são pouco contemplados pelos três primeiros tipos.

Em perspectiva análoga, Hyland (2006, p. 207) acrescenta que "o modo que o professor escolhe para expressar seu feedback pode afetar as reações dos estudantes e até certo ponto influenciar nas revisões deles. Além disso, pode ter impacto significativo no desenvolvimento da escrita". Assim, entendemos que esse feedback precisa ser feito de forma clara, pois servirá como encaminhamento para as modificações nos textos do aluno. Porém, marcações simbólicas nos entornos do texto podem não ser tão significativas quanto comentários mais explicativos à margem ou no "pós-texto" (RUIZ, 2013).

\section{Encaminhamento metodológico}

No intuito de promover o debate em torno da carta de reclamação, foram preparadas sete etapas para o desenvolvimento das atividades, aplicadas em cinco encontros, cuja organização ocorreu ancorada em três aspectos principais: o primeiro deles é a concepção de gênero como ação social (MILLER, 2009). Ainda que não seja possível atendê-la de forma plena, já que a escola simula situações comunicativas mediadas pelos gêneros, buscamos ilustrar a ideia do contexto autêntico em que o gênero acontece, propondo hipóteses sobre ações reais. O segundo é de que os textos apresentam propósitos comunicativos diversos e, ao identificá-los, provavelmente, os alunos poderão compreender a ação social impressa neles. $\mathrm{O}$ terceiro, e não menos importante, é que os gêneros apresentam traços linguísticos que servem de pano de fundo para que o gênero se constitua. Assim, segue: 
Figura 2 - Etapas para o desenvolvimento das atividades

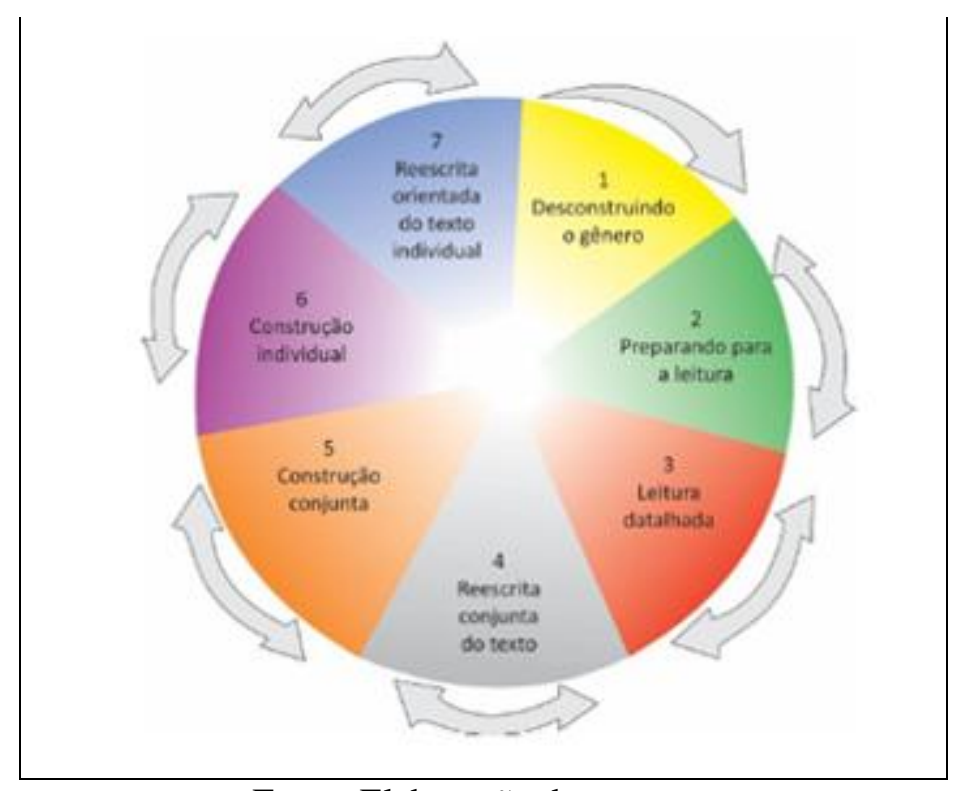

Fonte: Elaboração dos autores

Na primeira etapa, propusemos aos estudantes refletir sobre a natureza das ações e de que modo poderiam agir nelas. Por exemplo, iniciamos nossa conversa com a classe, com alguns dos seguintes questionamentos: ao comprarmos um produto e, ao recebê-lo, percebemos que veio com defeito, o que podemos fazer? Foi à emergência médica e não foi atendido por falta de profissionais na Unidade de Saúde, o que você faz? A iluminação da sua rua está cada vez pior, a comunidade já está cansada de solicitar reparo e não ser atendida, o que você pode fazer para mudar isso?

As respostas a essas perguntas foram variadas, algumas vezes resumidas a falar com o responsável. No entanto, seguimos o questionamento: se falarmos com a pessoa responsável, teremos a garantia de uma solução? Assim, conduzimos a conversa até que compreendessem que além da possibilidade de se falar com o responsável, podemos também fazer uso de mecanismos escritos para reclamar esses direitos.

Nesse momento, criamos um campo, a partir do imperativo de agir retoricamente a fim de alcançar diferentes propósitos. Uma vez compreendidas essas relações, avançamos até uma primeira versão escrita, quando o estudante precisou fazer uma reclamação, ainda sem um direcionamento prévio sistemático para o gênero. Os estudantes foram chamados a refletir sobre a forma como poderiam tentar solucionar o problema, por meio de um texto escrito adequado à execução dos seus propósitos. 
Figura 3 - Resposta de um dos estudantes

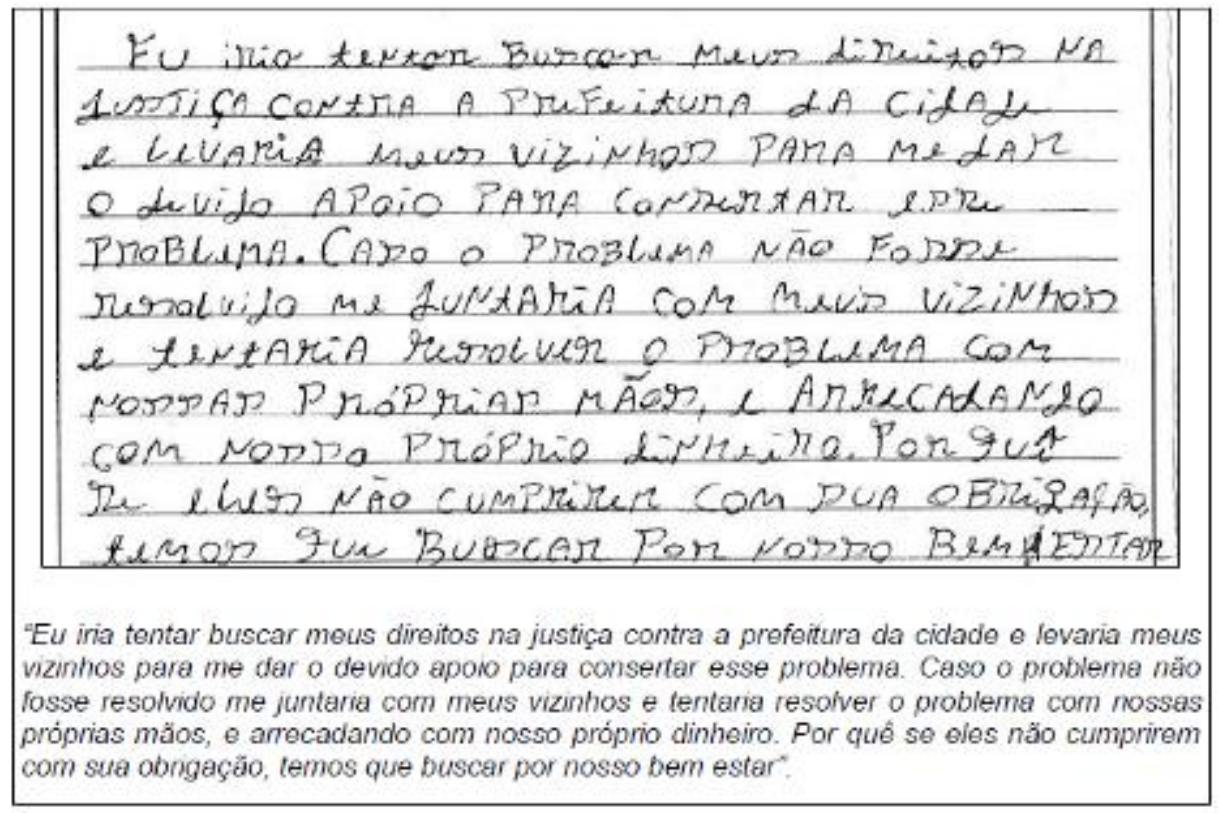

Fonte: Dados da pesquisa

Conforme pode ser observado, o estudante não atentou para o uso de um "texto escrito" para resolver o problema, alega apenas que iria à justiça, mas não indica por quais meios ou ainda, preocupa-se em resolver o problema fora dos dispositivos legais, quando afirma "com nossas próprias mãos" e por meio da arrecadação de dinheiro, cujas despesas deveriam ser efetivamente custeadas pelo órgão responsável.

Com isso, apresentamos diferentes maneiras de reclamar algo, como, por exemplo, por meio do site Reclame Aqui, dos Serviços de Atendimento ao Consumidor e do Fale Conosco que encontramos em alguns sites. Mesmo sem acesso à Internet na escola, levamos prints do site Reclame Aqui para que os alunos observassem como ele funciona. Exploradas as hipóteses prévias e construídos os campos, preparamos para a leitura de um exemplar desse gênero.

Apesar de parecer uma estratégia pouco utilizada, destacamos também a organização retórica, antes da própria leitura. Entretanto, acreditamos que apresentá-la precocemente poderia levar o estudante a compreender melhor os propósitos do gênero. Sem esquecer de mencionar o fato de que, na busca dessa compreensão, envolvendo múltiplas dimensões do gênero, como a ação social, os propósitos e seus traços linguísticos, o ciclo permite o avanço e o retorno a certas etapas.

a) Preparando para a leitura: tratamos inicialmente da sinopse do campo, em que fizemos um apanhado sucinto do assunto presente no texto, sempre interagindo com os estudantes, para que eles apresentassem questões que pudessem ser confirmadas ou refutadas durante a leitura do texto, na etapa posterior.

b) Leitura detalhada de exemplar do gênero: à medida que o texto estava sendo lido, destacamos alguns movimentos retóricos recorrentes em textos do gênero, inspirados no modelo CARS de Swales (2004), que adaptamos para a análise de 50 reclamações on line extraídas do Reclame Aqui, cujos movimentos e passos foram utilizados para a organização das reclamações, também postas nas cartas.

c) Reescrita conjunta do texto: essa etapa, bastante interativa, foi realizada tendo agora o estudante como escriba na lousa, mediado pelo professor e auxiliado pelos colegas. A classe discutiu as mudanças realizadas e o que isso alterou no texto. Além disso, por iniciativa própria, alguns estudantes compartilharam a importância da leitura do próprio texto, pois esse procedimento muitas vezes permite perceber detalhes que passaram despercebidos no processo da escrita. 
d) Construção conjunta: exploradas as condições de produção, juntos, produzimos um novo exemplar de carta de reclamação, a partir de um problema ocorrido na rua de dois estudantes da sala, em que devido à ausência de lombada, muitos acidentes vinham acontecendo. Nesse momento, enfatizamos os aspectos estudados até então, buscando escrever um texto que atendesse às demandas pretendidas com o gênero. Essa atividade conciliou escrita e reescrita, uma vez que o texto foi constantemente revisitado a fim de modificá-lo, na tentativa de melhorá-lo.

e) Reescrita conjunta: a primeira versão, coletiva, executada de forma colaborativa, como proposto por Rose (2016), pôs em cena diversas questões: a primeira delas é que os próprios estudantes quando escreviam não se davam conta de algumas transgressões à norma. No entanto, os demais que acompanhavam, como leitores, apontavam-nas rapidamente. Além disso, por ser uma atividade que envolveu toda a classe, os discentes ampliaram as escolhas lexicais, pois enquanto um aluno escrevia, o outro dava sugestões de palavras que melhor se encaixavam em certos contextos. A terceira questão, conclusiva para nós, é a importância da reescrita, pois a maioria manifestou que havia a necessidade de uma posterior leitura do texto, a fim de modificá-lo, já que quando escrevemos não atentamos ao texto como um todo.

Como resultado, segue:

Figura 4 - Construção conjunta

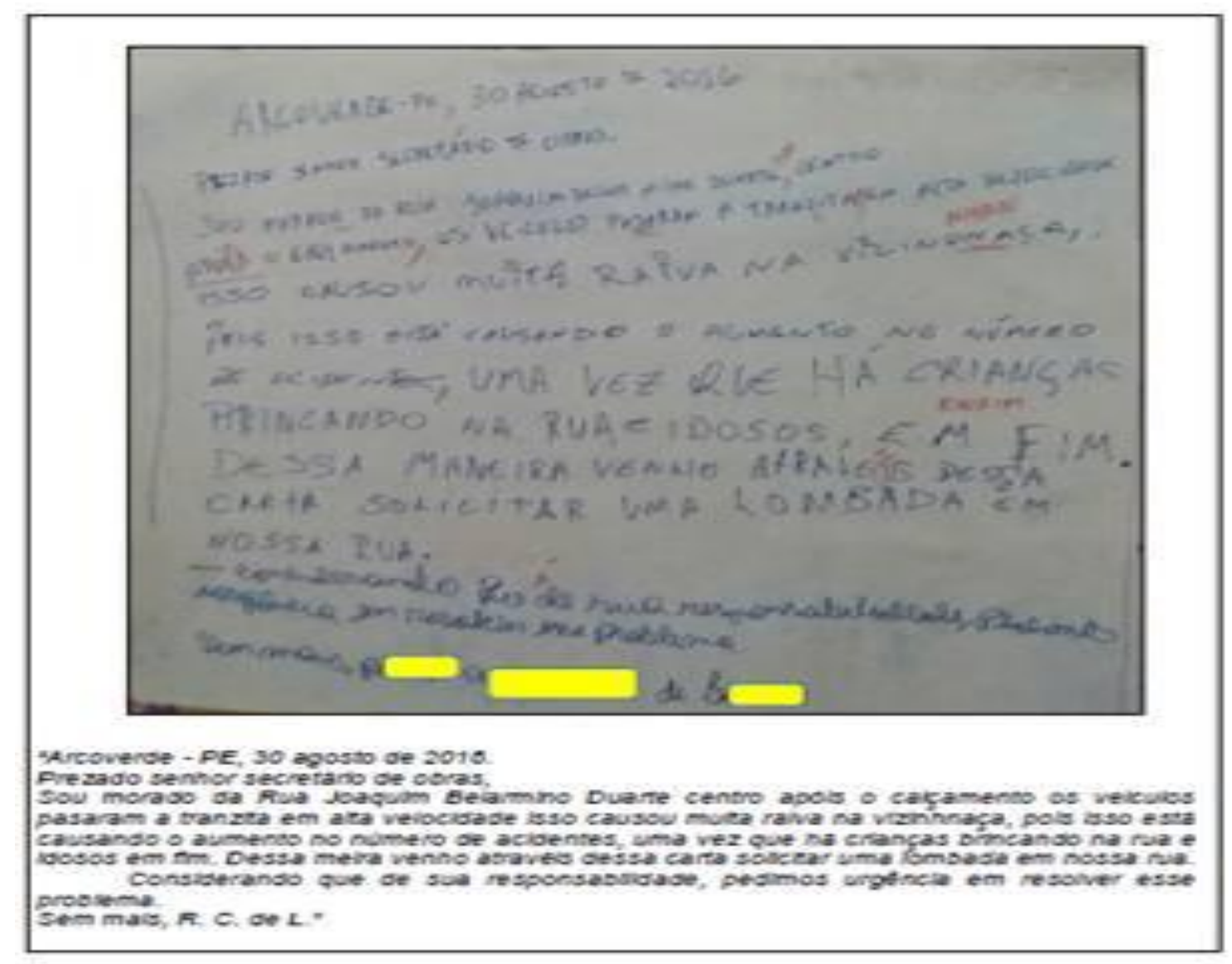

Fonte: Dados da pesquisa 
Figura 5 - Reescrita conjunta

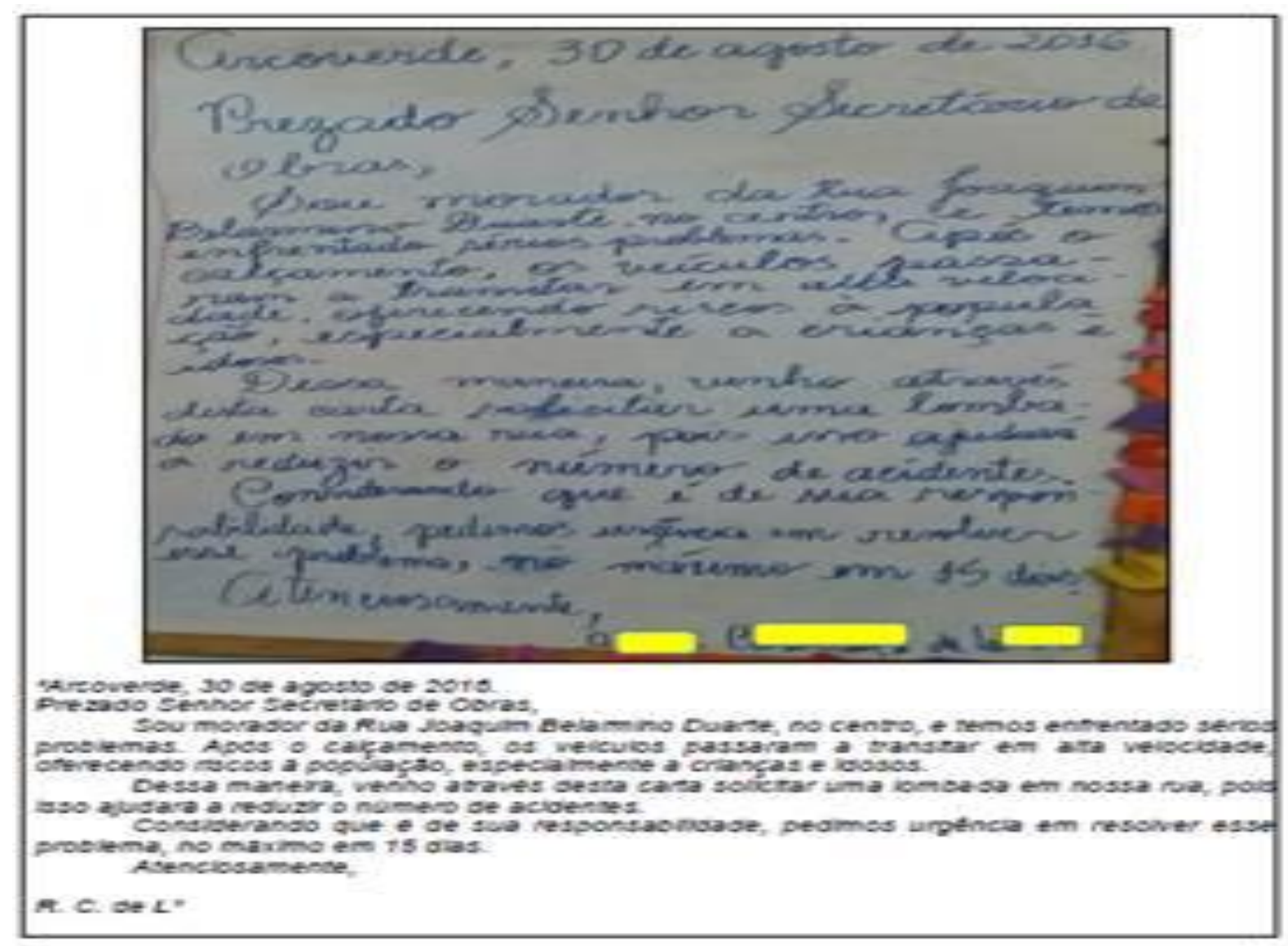

Fonte: Dados da pesquisa

Ao descreverem o problema, os alunos disseram inicialmente que os carros passaram a transitar em alta velocidade, porém, um deles interferiu e disse que não apenas os carros, mas também as motocicletas e, assim, sugeriu que um termo mais adequado seria veículos.

Nessa reescrita, os discentes acrescentaram alguns elementos, substituíram outros e, além disso, reorganizaram algumas ideias. Uma delas foi a percepção de uma certa estranheza, decorrente da ambiguidade, na construção “... uma vez que há crianças brincando na rua e idosos em fim". Segundo eles, dava a entender que assim como as crianças, os idosos brincavam na rua, então consideraram que seria necessário modificá-la. Além disso, observaram que deveriam estipular um prazo para a tomada de providências, já que ficava muito vaga essa ideia, na primeira versão.

f) Construção individual e reescrita do texto: cada estudante recebeu o seu texto, elaborado na primeira etapa, sem quaisquer anotações para que, sozinho, pudesse acionar o conhecimento já construído sobre o gênero. Então, a partir dos conhecimentos prévios e os aprimorados durante as etapas anteriores, escreveu uma carta de reclamação, individualmente. Além disso, reforçamos o fato de que esse texto tivesse de fato uma utilidade em sua vida, uma vez que poderá ser aplicado em diferentes situações do cotidiano. Não é muito raro que tenhamos algo a reclamar, na compra de produtos ou por uma questão social, sobre saúde, educação, saneamento. É provável que dessa construção individual tenham surgido soluções para problemas não só individuais, mas também coletivos.

g) Reescrita orientada do texto individual: a etapa de reescrita, conforme é tratada neste trabalho, orientada a partir de um bilhete (BUIN, 2006; RUIZ, 2013), foi adaptada ao ciclo por considerarmos esse procedimento importante na perspectiva de texto enquanto 
processo, pois nos parece improvável que um texto atinja seus propósitos numa primeira versão. Até os escritores mais experientes, normalmente, retornam aos seus textos a fim de adequá-los.

No tópico a seguir, apresentamos os desdobramentos da pesquisa a partir da análise dos textos dos alunos, assim como dos bilhetes orientadores que levaram à versão final.

\section{Análise dos textos}

Como apresentado anteriormente, na primeira versão escrita, os estudantes optaram por contar como fariam a reclamação. Assim, tomamos como ponto de partida para esta análise apenas os textos considerados como segunda versão, quando já fazem uma representação de cartas de reclamação, enquanto instrumentos para reclamar seus direitos. Assim sendo, nos doze textos coletados, identificamos a seguinte organização retórica para a reclamação na versão 2 , conforme se pode observar na Tabela 1:

Tabela 1 - Unidades recorrentes na construção da reclamação (versão 2)

\begin{tabular}{|l|c|c|}
\multicolumn{1}{|c|}{ Categoria } & Quantitativo & $\begin{array}{c}\text { Frequência } \\
\%\end{array}$ \\
\hline Un 1 - Detalhamento tempo e espaço & 10 & 83 \\
\hline Un 2 - Referéncia ao destinatário & 11 & 90 \\
\hline $\begin{array}{l}\text { Un 3 - Descriçāo da compra/aquisiçăo de produto ou } \\
\text { de um problema de ordem social }\end{array}$ & 12 & 100 \\
\hline Un 4 - Crícica ao serviço recebido & 12 & 100 \\
\hline Un 5 - Solicitação de posicionamento da empresa & 10 & 83 \\
\hline Un 6 - Saudação final & 6 & 50 \\
\hline Un 7 - Assinatura & 6 & 50 \\
\hline
\end{tabular}

Fonte: Elaboração dos autores

Dessa forma, percebemos que os estudantes demonstram compreender a organização básica do gênero em estudo, sobretudo, as unidades que constroem a reclamação. Parece-nos evidente também que o maior entrave se concentra no detalhamento dessas unidades, ou seja, na organização das subunidades, pois todos descrevem a existência de um problema a ser resolvido, assim como solicitam empenho em resolvê-lo, mas, normalmente, não dizem como fazê-lo. A partir disso, elaboramos a tabela 2 para observarmos a incidência das subunidades na versão 2. Conforme segue: 
Tabela 2 - Subunidades recorrentes na construção da reclamação (versão 2)

\begin{tabular}{|c|c|c|}
\hline Categoria & Quantitativo & $\begin{array}{c}\text { Frequência } \\
\%\end{array}$ \\
\hline Sub 1 - Dados do produto & 1 & 8 \\
\hline $\begin{array}{l}\text { Sub } 2 \text { - Identificação da empresa onde adquiriu/local } \\
\text { onde ocorreu o problema }\end{array}$ & 6 & 50 \\
\hline $\begin{array}{l}\text { Sub 3 - Data da aquisiçáo/periodo de ocorréncia do } \\
\text { problema }\end{array}$ & 3 & 25 \\
\hline Sub 4 - Descriçáo da reclamaçăo & 7 & 58 \\
\hline Sub 5 - Como ocorreu o problema & 3 & 25 \\
\hline Sub 6 - Tentativas para solucionar o problema & 2 & 17 \\
\hline Sub 7 - Apresentação de protocolo & 0 & 0 \\
\hline Sub 8 - Sugestáo de providéncia & 3 & 25 \\
\hline Sub 9 - Citação de lei para punição à empresa/órgáo & 0 & 0 \\
\hline
\end{tabular}

Fonte: Elaboração dos autores

Como podemos constatar nas tabelas 1 e 2 , normalmente, os estudantes organizam os textos contemplando as principais unidades que constituem as reclamações, contudo, não as desenvolvem com maior detalhamento.

A exemplo disso, tomemos como referência a versão 2 do aluno 1:

Figura 6 - Versão 2 do aluno 1

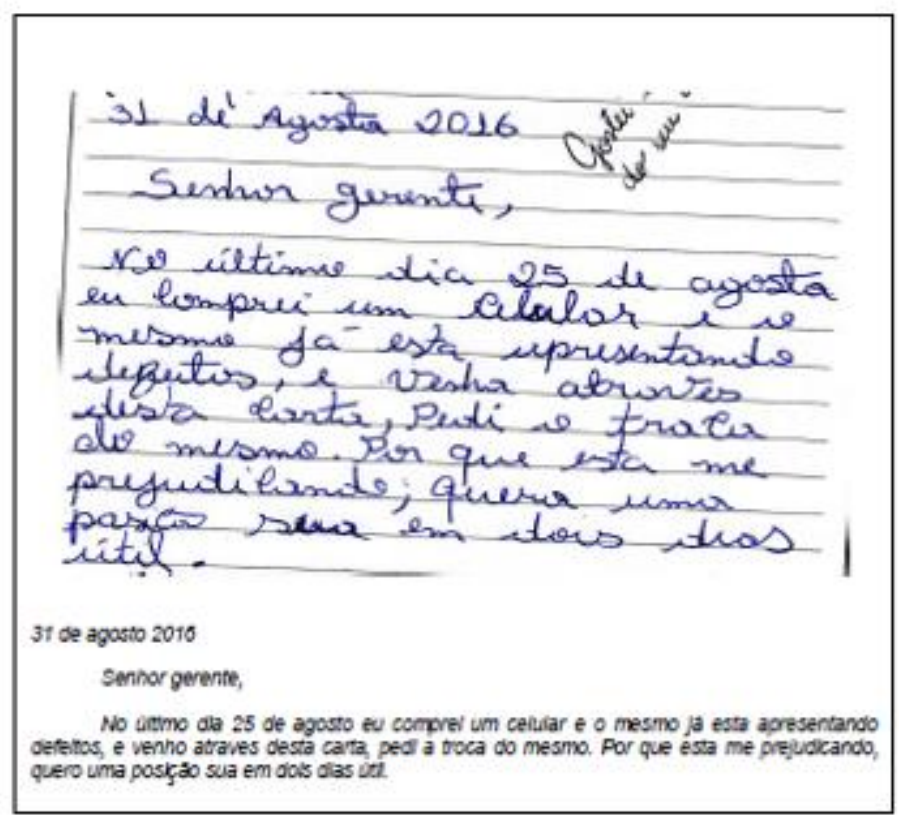

Fonte: Dados da pesquisa 
Na versão 2 do aluno 1, percebemos que o estudante reconhece a organização estrutural do gênero, bem como a necessidade de apresentar a reclamação. Identificamos a ocorrência de:

a) (Un-1): "31 de agosto de 2016";

b) (Un-2): "Senhor gerente";

c) (Un-3): "No último dia 25 de agosto eu comprei um celular (...)";

d) (Un-4): "o mesmo já está apresentando defeitos";

e) (Un-5): “(...) quero uma posição em dois dias úteis”.

No entanto, não identificamos mais detalhes sobre o produto, uma vez que o estudante reclama sobre o fato de o celular "já está apresentando defeitos", mas isso não constitui informação suficiente, já que não indica quais seriam esses defeitos. De modo geral, o estudante demonstrou familiaridade com a escrita do gênero, ainda que com a presença de alguns desvios gramaticais e gráficos. Com base nisso, no bilhete 1, sugerimos que ele desenvolvesse alguns movimentos a fim de organizar o texto, inspirados no modelo de reclamação. A partir dele, foram recomendados alguns ajustes a serem considerados na reescrita, como podemos ver no bilhete 1:

Figura 7 - Bilhete 1

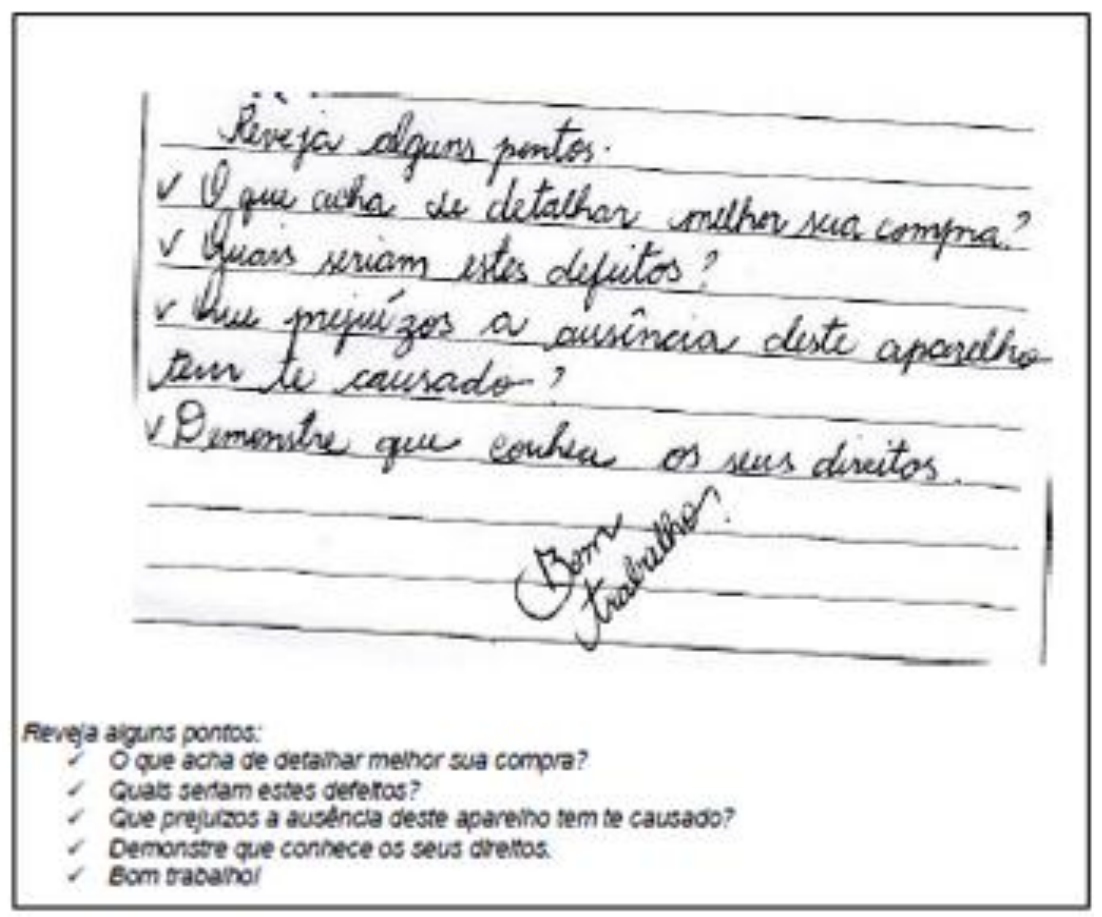

Fonte: Dados da pesquisa

As sugestões postas no bilhete 1 estavam centradas nas subunidades $1,4,5,8$ e 9 , que se referem aos dados do produto, descrição da reclamação, como ocorreu o problema, sugestão de providência e citação da lei, respectivamente.

A partir das orientações pontuadas no bilhete, o aluno 1 fez algumas modificações, segundo se confirma na figura que segue: 
Figura 8 - Versão 3 do aluno 1

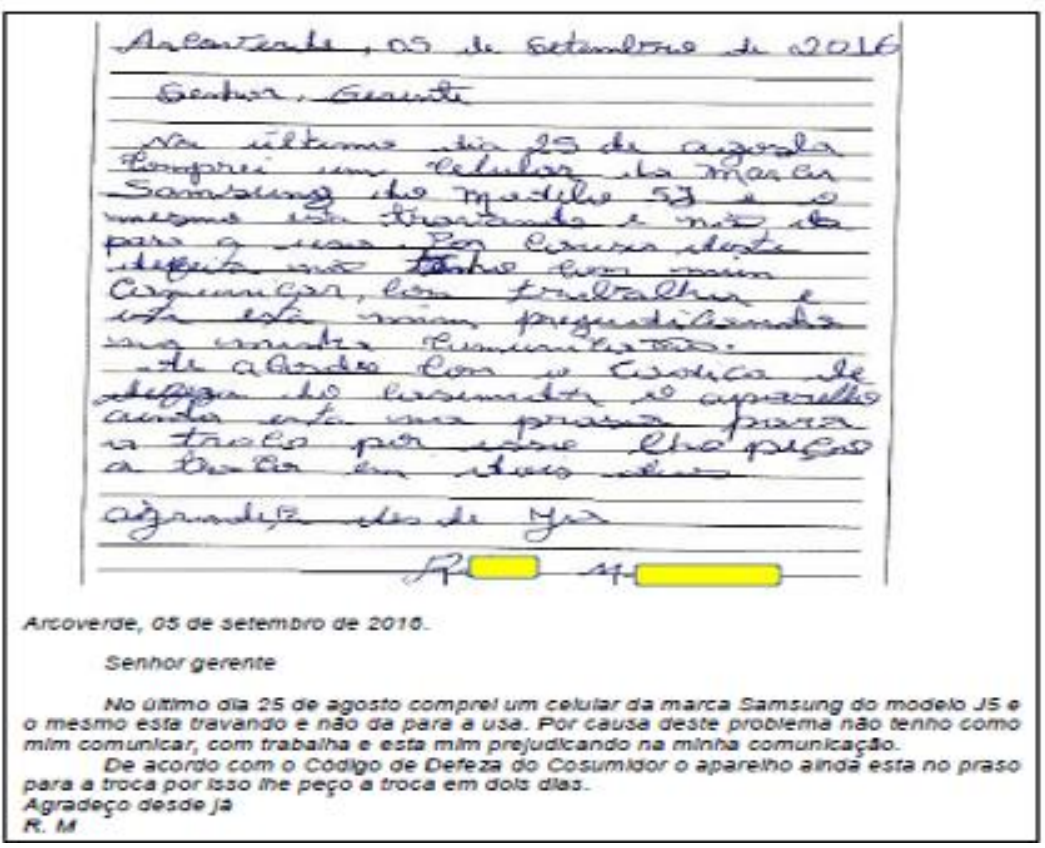

Fonte: Dados da pesquisa

Com isso, a versão 3 do aluno 1 trouxe algumas alterações significativas na construção da reclamação. Inicialmente, apresentou uma descrição do produto "celular da marca Samsung modelo J5" (sub-1), indicando o defeito já no primeiro parágrafo, na linha quatro, ao pontar que o aparelho estava travando (sub-4), o que reforça a reclamação. Informa ainda que devido a isso, ele está impossibilitado de usá-lo (sub-4), além de demonstrar, no último parágrafo, que conhece o seu direito enquanto consumidor (sub-9), ao fazer alusão ao Código de Defesa do Consumidor. Por fim, ele reivindica a tomada de providência da empresa, ao solicitar a troca do produto (sub-8). Duas unidades foram acrescidas à versão 3: (Un-6) e (Un-7), não sinalizadas no bilhete, com aspectos mais formais do gênero, como a inserção da saudação final e a assinatura, respectivamente.

Assim, na terceira versão, produto da intervenção direta por meio do bilhete, obtivemos os seguintes resultados, segundo podemos verificar nas tabelas 3 e 4 :

Tabela 3 - Unidades recorrentes na construção da reclamação (versão 3)

\begin{tabular}{|l|c|c|}
\multicolumn{1}{|c|}{ Categoria } & Quantitativo & $\begin{array}{c}\text { Frequência } \\
\%\end{array}$ \\
\hline Un 1 - Detalhamento tempo e espaço & 12 & 100 \\
\hline Un 2 - Referéncia ao destinatáno & 11 & 90 \\
\hline $\begin{array}{l}\text { Un 3 - Descrição da compra/aquis içăo de produto ou } \\
\text { de um problema de ordem social }\end{array}$ & 12 & 100 \\
\hline Un 4 - Critica ao serviço recebido & 12 & 100 \\
\hline Un 5 - Solicitação de posicionamento da empresa & 11 & 90 \\
\hline Un 6 - Saudação final & 9 & 75 \\
\hline Un 7 - Assinatura & 11 & 90 \\
\hline
\end{tabular}

Fonte: Elaboração dos autores 
Tabela 4 - Subunidades recorrentes na construção da reclamação (versão 3)

\begin{tabular}{|c|c|c|}
\hline Categoria & Quantitativo & $\begin{array}{l}\text { Frequência } \\
\%\end{array}$ \\
\hline Sub 1 - Dados do produto & 2 & 17 \\
\hline $\begin{array}{l}\text { Sub } 2 \text { - Identificação da empresa onde adquiriulocal } \\
\text { onde ocorreu o problema }\end{array}$ & 10 & 83 \\
\hline $\begin{array}{l}\text { Sub } 3 \text { - Data da aquisiģáa/periodo de ocorréncia do } \\
\text { problema }\end{array}$ & 3 & 25 \\
\hline Sub 4 - Descriçăo da reclamaçăo & 9 & 75 \\
\hline Sub S - Como ocorreu o problema & 5 & 40 \\
\hline Sub 6 - Tentativas para solucionar o problema & 2 & 17 \\
\hline Sub 7 - Apresentaçảo de protocolo & 0 & 0 \\
\hline Sub 8- Sugestāo de providéncla & 6 & 50 \\
\hline Sub 9 - Citaçāo de lei para puniçăo á empresa/órgăo & 1 & 8 \\
\hline
\end{tabular}

Fonte: Elaboração dos autores

Diante do exposto, concordamos que a reescrita, representada pela versão 3, apresenta a reclamação de modo mais detalhado. É certo que o texto requer outros ajustes. No entanto, no que concerne ao propósito comunicativo, tais modificações dão conta de fazê-lo.

Ademais, consideramos que, apesar de ser uma primeira reescrita, o texto denota avanços em relação à versão anterior e que por meio de outras formas de correção, seja indicativa, classificatória ou resolutiva, talvez não fosse possível atingir tais resultados.

Dessa forma, ainda que tenhamos apresentado um número abreviado de exemplos, parece-nos evidente, a partir dessa análise, que a reescrita orientada contribui para o aprimoramento do texto. Tal procedimento se mostra, assim, uma estratégia eficaz para o ensino de gêneros, numa perspectiva que os concebe a partir da ação social, dotados de propósitos comunicativos e construídos através do uso adequado de mecanismos linguísticos.

\section{Considerações finais}

Dispusemo-nos a considerar o gênero como uma categoria ensinável e trouxemos à cena discussões sobre uma possível pedagogia de gêneros, embasada nos princípios do ensino implícito e explícito. Reforçando esse entendimento, estabelecemos uma relação com outros gêneros que, assim como a carta de reclamação, têm o reclamar como principal propósito comunicativo.

Para a intervenção pedagógica, optamos por utilizar como metodologia para o ensino do gênero o ciclo de ensino-aprendizagem da Escola de Sydney, especialmente, a partir dos recentes trabalhos de Martin (2016) e Rose (2016). Tal escolha ocorreu por considerarmos que a organização do ciclo permite ao professor explorar o gênero sob diferentes enfoques, partindo do contexto até chegar aos seus traços linguísticos, além de proporcionar uma análise não linear do gênero.

Sobre o ciclo, Cope e Kalantzis (1993) destacam que, apesar de haver um forte direcionamento para os aspectos formais da linguagem, essa pedagogia de gênero se distancia das abordagens formalistas que exploram as regras gramaticais de modo isolado. Em sua essência, a proposta de uma pedagogia de gênero, como a que defendemos nesta pesquisa, pode ser a maneira mais conveniente de possibilitar o acesso desses grupos culturalmente marginalizados pela sociedade efetivamente letrada - do qual fazem parte os estudantes da modalidade da EJA - aos mais variados gêneros. 
Somado a isso, no que concerne à produção de textos do gênero, elencamos como uma etapa fundamental a reescrita orientada pelo professor. Apesar de a reescrita estar prevista no ciclo, neste trabalho, antecipamos a ela a correção textual-interativa do professor, mediada por bilhetes que apresentavam direcionamentos para a reescrita do texto.

Os resultados da pesquisa sinalizaram para o êxito na aplicação do ciclo, pois até os estudantes que apresentaram mais dificuldades na escrita demonstraram reconhecer algumas especificidades do gênero, sobretudo, para a construção do seu propósito comunicativo. Além disso, a reescrita orientada por bilhetes também se mostrou significativa, pois as alterações feitas no texto partiram, em boa parte, dessa orientação, tornando as reclamações mais consistentes e detalhadas.

Dessa forma, avaliamos que o desenvolvimento desta pesquisa nos possibilitou ampliar nosso entendimento na elaboração de estratégias para o ensino de gêneros, sobretudo, para a produção de textos nas turmas da EJA, não apenas pela evolução na aprendizagem, mas pelas reflexões sobre a linguagem, proporcionadas em sala de aula que, possivelmente, serão consideradas em outros contextos de produção fora dela. Além disso, foi possível propiciar aos alunos a oportunidade de refletir sobre o papel social do gênero para o exercício de sua cidadania, enquanto agentes da sociedade em que vivem.

Como já dito, não se pretendia com este trabalho apresentar receitas para o ensino sistemático de gêneros, mas apontar estratégias que o possibilitem. Utilizando-nos das palavras de Bezerra (2006, p. 220), ao concluir sua tese de doutorado, "não surpreende, portanto, que ao chegar ao fim tenhamos a impressão de retornar ao começo". Ao chegar à última versão das produções, a que denominamos de versão 3, ainda tão carente de revisão, refletimos sobre o quanto ainda há por teorizar e estender tais implicações à prática. Assim, esperamos que este trabalho possa ainda motivar pesquisadores e educadores a explorar diversas outras possibilidades de aplicação do ciclo de ensino-aprendizagem australiano para o ensino de gêneros.

\section{Referências}

BAZERMAN, C. Onde está a sala de aula? In: Gênero, agência e escrita. São Paulo: Cortez, 2006. p. 52-58.

. Formas sociais como habitats para ação. In: interação. 4. ed. São Paulo: Cortez, 2011. p. 49-65. Gêneros textuais, tipificação e

Retórica da ação letrada. São Paulo: Parábola Editorial, 2015.

BAWARSHI, A. S.; REIFF, M. J. Gênero: história, teoria, pesquisa, ensino. São Paulo: Parábola, 2013.

BEZERRA, B. G. Gêneros introdutórios em livros acadêmicos. Recife, 2006. 243f. Tese (Doutorado em Linguística) - Universidade Federal Pernambuco.

BRONCKART, J. P. Atividades de linguagem, discurso e desenvolvimento humano. (Org.). Tradução de Anna Rachel Machado et al. Campinas, SP: Mercado de Letras, 2006.

BUIN, E. O impacto do bilhete do professor na construção do sentido do texto do aluno. In: SIGNORINI, I. (Org.). Gêneros catalisadores: letramento e formação do professor. São Paulo: Parábola Editorial, 2006. p. 95-124.

CHAPMAN, M. Situated, social active: rewriting genre in the elementary classroom. Written Communication, v. 16, n. 4, p. 469-490, 1999.

COPE, B.; KALANTZIS, M. The powers of literacy. London: Palmer Press, 1993.

DEVITT, A. J. Writing genres. Carbondale: Southern Illinois. Cambridge: University Press, 2004. 
FREADMAN, A. Anyone for tennis? In: FREEDMAN, A.; MEDWAY, P. (Org.). Genre and the New Rhetoric. Bristol: Taylor and Francis, 1994. p. 43-66.

HYLAND, K. Genre and second language writing. Ann Arbor: University of Michigan Press, 2004.

. HYLAND, F. Interpersonal aspects of response: constructing and interpreting written feedback. In: ___. Feedback in second language writing: contexts and issues. New York: Cambridge University Press, 2006.

MARTIN, J. R. On of three traditions: genre, functional linguistics, and the "Sydney School". In: ARTEMEVA, N.; FREEDMAN, A. Genre studies around the globe: beyond the three traditions. Inkshed pubications, 2016. p. 31-79.

MILLER, C. Gênero como ação social. In: Ed. Universitária da UFPE, 2009. p. 21-44.

. Gênero textual, agência e tecnologia. Recife:

ROSE, D. Learning in linguistic contexts: integrating SFL theory with literacy teaching. Proceedings of the 36th International Systemic Functional Congress, Beijing: 2009. Disponível em: <https://www.readingtolearn.com.au/wp-content/uploads/2016/01/Learning-in-LinguisticContexts.pdf> Acesso em: 10 jul. 2018.

. Analysing pedagogic discourse: an approach from genre and register. In: Functional Linguistics: A Springer Open Journal, Sydney, p. 1-32, 2014.

. Genre, knowledge and pedagogy in the Sydney School. In: ARTEMEVA, N.; FREEDMAN, A. Genre studies around the globe: beyond the three traditions. Inkshed pubications, p. 2016. p. 299-336.

RUIZ, E. D. Como corrigir redações na escola: uma proposta textual-interativa. 1. ed. 2. reimpr. São Paulo: Contexto, 2013.

SCHNEUWLY, B.; DOLZ, J. Gêneros orais e escritos na escola. Campinas: Mercado das Letras, 2004.

SERAFINI, M. T. Como escrever textos. 7. ed. São Paulo: Globo, 1995.

SWALES, J. M. Genre Analysis: English in academic and research settings. Cambridge: Cambridge University Press, 1990.

Press, 2004.

Research genres: explorations and applications. Cambridge: Cambridge University

Recebido em 10 de maio de 2018

Aceito em 15 de julho de 2018 